\title{
Change of Customer Concept in Marketing Activities
}

\author{
Xun LI \\ Department of Management Engineering, Dalian institute of technology, Dalian, Liaoning 116052 \\ Email: lian004@163.com
}

\section{Keywords: Marketing Activities; Customers; Definitions; Change of Concept}

\begin{abstract}
Marketing concept refers to the guiding ideology of correctly dealing with the interest relationship among enterprise, customers and society and also the fundamental standard for behaviors in the process of an enterprise to carry out all marketing activities in a certain period of time, production and business technology, and market environmental conditions. In this paper, the change of customer concept in marketing activities is mainly discussed. Therefore, this paper is of certain practical and guiding significance.
\end{abstract}

\section{Introduction}

As is known to all, the market marketing activities of an enterprise are carried out under the guidance of a specific guiding ideology or business management idea. For hundreds of years, marketing concept has constantly developed and changed along with the development of production, the progress of science and technology, and the change of market environment. The so-called market marketing concept refers to the guiding ideology of correctly dealing with the interest relationship among enterprise, customers and society and also the fundamental standard for behaviors in the process of an enterprise to carry out all marketing activities in a certain period of time, production and business technology, and market environmental conditions. The core of marketing concept is to correctly deal with the interest relationship among enterprise, customers, and society. In many cases, these interests are not only mutually contradictory, but also mutually supplement each other. Therefore, it is necessary for enterprises on the basis of comprehensively analyzing market environment to correctly deal with the relationship among the above three sides, determine their own principles and basic orientations and also use them to guide the marketing practices. Then, the goal of enterprise can be effectively achieved, and the success of enterprise can be guaranteed. As exchanges in products get a further development, a profound change has happened to the transitions of society, economy and market environment, and the accumulation of enterprise management. The basic track of this change goes from enterprise interest orientation to customer interest orientation and then to social interest orientation. In fact, in market marketing activities, it is necessary to change not only marketing concept, but also customer concept. In this paper, the change of customer concept in marketing activities is mainly discussed. Therefore, this paper is of certain practical and guiding significance.

\section{Re-definition of "Customer" in Modern Marketing}

In a certain sense, customer emerges as the starting and key point of all marketing activities; customer is the center and the focus of the marketing activities in the modern times. However, "who is our customer" is always a concept, which is very difficult to define. Therefore, to make a discussion on the change of customer concept in the marketing activities, it is necessary to know well the question "who are our customers" first.

In the traditional sense, customers were thought to be "people who come and buy goods", and the other party opposite to sellers in the buying and selling activities. From the definition, it is easy to see that this meaning was derived from the age in which demand exceeded supply. At that time, the social productive forces were relatively backward, and market activities were started mainly from the production of enterprises, but not from customer demands. Customer as the other party in the trading activities of goods, had no enough optional space because of the shortage of goods, and therefore could only choose the goods produced by enterprises. Later, along with the continuous development of productivity, seller's market began to change to buyer's market, and 
the demands of customers became the power for guiding the production of enterprises with a gradual step. Therefore, it is necessary for people to re-know customers.

In modern marketing concept, marketing essence and core are thought to be meeting the demands of customers, and all work of an enterprise should be started from customers. In the production and operation activities of enterprises, to attain a sustainable development, it is necessary for enterprises to make segmentation on customers according to the characteristics of the different demands of customers and then locate target market, and also make effective, reasonable, and specific marketing mixes according to the characteristics of customer goal. Thus, the demands of customers can be fulfilled. Specifically, several characteristics of the customers in the modern marketing activities can be concluded in the following.

\subsection{Diversity}

Although customer is defined as the buyer in buying and selling relationship in the traditional sense, customers under the modern marketing concept can't be only limited to buyers. Customers should be diversified. For enterprises, customers can be internal or external, direct or indirect, and belong to themselves or competitors. In short, better products and services can be provided by enterprises only if customers are focused from a wider perspective, and ultimately the satisfaction of customers can be improved.

\subsection{Subjectivity}

As the starting and ending points of production and management activities of an enterprise, customers play a decisive role in the direction of production activities of enterprise. That is, what to produce, how to produce, where to sell, and how to sell are all decided by customers Therefore, it is necessary for enterprises to respect the subjectivity of customers, and carry out production and management activities and marketing activities under the orientation of customer demands.

\subsection{Concreteness}

In modern marketing activities, it is necessary for enterprises to know well the real demands of customers according their age, gender, occupation, social class, preference and so on. On this basis, concrete and practical marketing combination and marketing strategy can be made by enterprises in a planned way.

In short, in modern marketing activities, decisive power to speak is possessed by customers in the actual production and management process of enterprises. That is, what to provide and how to provide should be accepted by customers. Only in this way, a sustainable, healthy development can be attained by an enterprise.

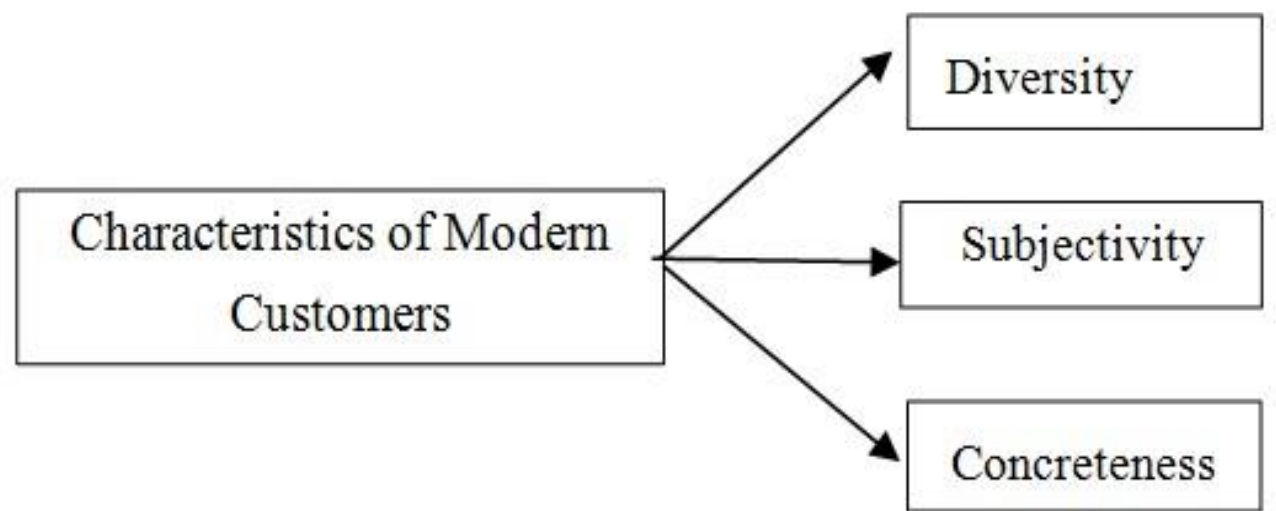




\section{Change of Customer Concept in Marketing Activities}

Compared with the traditional market competition, the concept of modern market competition is centered at customers, but the traditional market marketing concept gave top priority to selling goods and achieving the purpose of making money. Selling concept is to acquire the maximum profit through promotion and marketing activities from inside to outside (i.e. starting from production department of enterprise and centered at existing products). However, in modern marketing concept, , profit is made through meeting the demands of customers by applying the sequence from outside to inside of enterprise (i.e. Starting from market activities and centered at customer demand). According to the above analysis, it can be known that the customers in modern marketing activities feature diversity, concreteness and subjectivity, and modern marketing concept should be centered at customers and aim at meeting the demands of customers. Therefore, the best product will never exist in an enterprise, because the products that have been produced will be always replaced with new updated products with a gradual step. The subsequently derived effect is that customer concept in marketing will certainly have a change. That is, it is believed by the customers that enterprises will produce the goods meeting their demands. Thus, a great trust is given to enterprises.

Senior intelligence department of American Bell Company used to set up advertising, which can be said to be the best model for the concept of regarding "meeting the demands of customers" as central task. The advertising slogan generally said, "Today, our central task must be oriented at customers, and we will know about what they care about and listen to their voice and attach importance their needs, which will always be more important than our needs forever; the cooperative relationship between us and customers has to be established based on mutual trust, mutual respect, and our own hard work; customer is our god, lifeblood, and also the only reason we exist; we have to always keep the question 'who is our center' in mind, know well what to demand, when to demand and where to demand as well as how to provide the best service for them, and this will be the responsibility of anyone of us; we will always abide by the promise to customers". This is the most sincere promise made by an enterprise to its customers. Beyond all doubts, an invisible customer market has been won by this enterprise in marketing activities. In the meantime, the sincerity of the enterprise can be truly felt by customers from these advertising words. Hence, the marketing concept of "promise-trust" was formed, not only promoting enterprises to change marketing concept, but also allowing customers to re-locate their own concept, begin to trust enterprises, and keep willingness to operate with enterprises. In addition, buying goods of customers is also a concept actually. Today, however, the purpose of many people to buy products of famous brands is to play the peacock or get a satisfaction, but probably not only to meet the need of keeping warm. Therefore, relevant products can be produced by enterprises according to such a kind of need of customers.

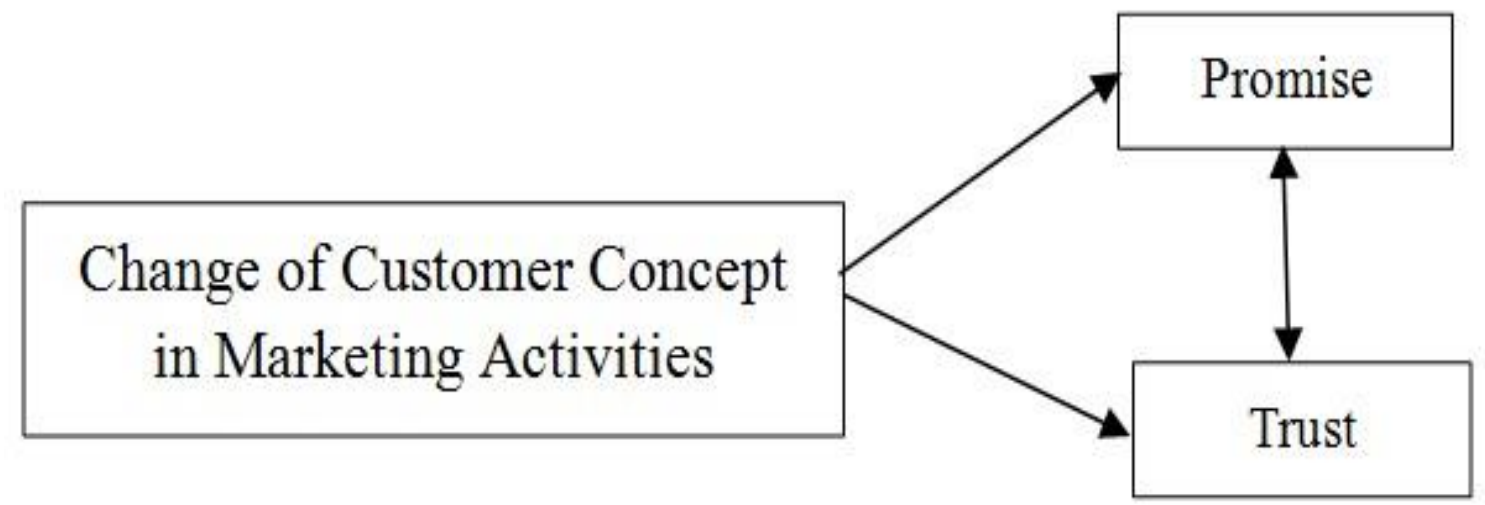




\section{Conclusion}

The formation of a concept is a result from the integration of a variety of perceptions. Customers (consumers) in modern marketing activities feature obvious subjectivity, concreteness, and diversity. Today, market has changed from seller's market to buyer's market.

Therefore, it is necessary for enterprises to carry out production and management activities under the orientation of customer demands, for the purpose of meeting the demands of customers and providing better services. In this way, customers will have no choice but only to trust themselves in fierce marketing competition, and then establish a mutually trusted relationship with enterprises.

All in all, a long-term development can be attained by an enterprise in fierce marketing competition only if both marketing concept and customer concept are known well by it.

\section{References}

[1] Jing Guo. Analysis on the Development trend of Market Marketing Idea [J]. China Business \& Trade, 2010, (10).

[2] Weidong Yang. Thinking on the Innovation of Enterprise Marketing [J]. Modern Economic Information, 2011, (05).

[3] Wei Zhang. Marketing Concept and Strategy of Enterprises in the Age of New Economy [J]. Guide to Business, 2011, (02). 